\author{
자원탐사의 최적화 및 자동화를 위한 \\ 케이블카형 로봇 시스템의 개발 \\ 유선철 ${ }^{1}$, 표주현 ${ }^{1}$, 정현기 $^{2^{*}}$, 윤중선 $^{3}$, 이정익 $^{4}$, 조성호 $^{5}$, 김태진 $^{6}$ \\ ${ }^{1}$ 포항공과대학교 해양대학원, ${ }^{2}$ 지질자원연구원, ${ }^{3}$ 부산대학교 기계공학부, ${ }^{4}$ 인하공업전문대학 기계공학부 기계설계과, \\ ${ }^{5}$ 과학기술연합대학원대학교, ${ }^{6}$ 대우조선해양
}

\title{
Development of the Resource Investigation Emulating Cable Car Type Robot System
}

\author{
Son-Cheol Yu ${ }^{1}$, Ju-Hyun Pyo ${ }^{1}$, Hyun-Key Jung ${ }^{2 *}$, Joong-Sun Yoon ${ }^{3}$, \\ Jung-ik Lee ${ }^{4}$, Sung-Ho $\mathrm{Cho}^{5}$ and Tae-Jin $\mathrm{Kim}^{6}$ \\ ${ }^{1}$ POSTECH POSTI, ${ }^{2}$ Korea Institute of Geoscience \& Mineral Resources, \\ ${ }^{3}$ Dept. of Mechanical Eng. Pusan National University, \\ ${ }^{4}$ Department of Mechanical Design, Inha Technical College, ${ }^{5}$ UST, ${ }^{6}$ DSME
}

\begin{abstract}
요 약 본 자원탐사의 중요성이 증대되고 있는 상황에서, 효과적인 자원탐사방법의 최적설계 및 탐사자동화가 중대 관심사가 되고 있다. 본 연구는 수치적인 모델링의 문제점을 해결하기 위하여, 현장의 환경을 하드웨어적으로 재현한 탐사환경 축소모형 로봇 시스템을 제안한다. 종래의 이동로봇 시스템을 개량하여 케이블카용 로봇시스템을 개발하였 다. 본 시스템은 로봇의 자장 노이즈를 극소화시키고, 자장 그레디언트의 현장 측정 재현을 통하여 효과적인 설계 지침을 제공한다. 또한 케이블카형 이동방법은 이용하여, 험지에서 탐사 자동화등에 활용될 수 있다.
\end{abstract}

\begin{abstract}
Recently, the resource investigation has got much attention. The optimization of the resource investigation method and its automation are one of the most important keys for it. We propose the resource investigation emulating robot to overcome the conventional method; a numerical modeling. A nobel cable car robot system is developed. It minimizes the magnetic noise and comes true the gradient emulating of the field. This advanced system enables the optimization and automation of the resource investigation.
\end{abstract}

Key Words : Resource Investigation, Robot, Automation, Magnetic, Sensing

\section{1. 서론}

최근 세계적으로 자원 개발경쟁이 가속화 되어가고 있 다. 특히 신흥 개발도상국을 중심으로 에너지 수요가 증 가하면서 자원확보는 국제적인 이슈가 되고 있다. 리튬같 은 희귀 광물의 경우, 수요가 폭발적으로 늘어나고 있으 나 공급은 한정된 상태이다. 따라서 자원탐사가 진행되지 않았던 오지나 험지, 해양 영역까지 자원탐사의 전략지역 으로 부상하고 있다. 이런 전략지역에 대한 자원 탐사의
중요성은 날로 증대되고 있다.

자원탐사는 최소한의 정보로 일정규모의 예상 매장영 역을 선정한 뒤에, 영역 내에 탐색을 통하여 자원을 찾는 작업이다. 지하에 대한 정보를 얻기 위해 가장 좋은 방법 은 암석물 자체를 직접 관찰하는 것이지만 현실적으로 많은 시간과 노력이 필요하다. 따라서 잛은 시간에 광범 위한 지역을 물리 탐사를 통해 지하의 정보를 획득할 수 있다. 이같은 탐색과정을 반복하여 매장 가능성이 높은 지역을 좁혀감으로써 자원을 찾아낸다. 경쟁적인 자원탐

본 논문은 지식경제부에서 지원하는 한국지질자원연구원의 2010년 "USN 기반 융합자원탐사 시스템개발"의 위탁연구과제로 수행되었음.

"교신저자 : 정현기(hkjung@kigam.re.kr)

접수일 10 년 11 월 09 일 수정일 11 년 01 월 06 일게재확정일 11 년 01 월 13 일 
사 상황에서는 특정 영역을 단시간 내에 효율적으로 탐 사하여 신뢰도가 높은 자원정보를 얻어야한다.

자원탐사 고도화 방법은 다음의 두 가지로 생각할 수 있다.

\section{1 현재의 탐사효율을 높이는 방법 (탐사 설 계 지원시스템 개발)}

단시간 내에 광범위한 영역을 고속으로 탐사하기 위하 여 USN(Ubiquitous Sensor Network)기반 융합형 자원탐 사 기술이 각광을 받고 있다. 이 탐사방법은 항공기, 차 량, 인력등 다양한 종류의 복수의 센싱 에이전트(Agent) 가 동시에 센싱을 하면서 네트워크를 구성하여 에이전트 간의 정보교환을 통하여 전체 탐사의 효율과 신뢰성을 높이는 일종의 센서융합(Sensor-Fusion)의 개념이다. 주 로 극한 야외환경에서 탐사가 이루어지는 환경적인 특성 상, 통신등에 어려움이 많았으나 최근 기술의 발달에 힘 입어, 활발한 연구가 이뤄지고 있다

이러한 융합형 자원 탐사 기술은 복수의 에이전트를 육상 및 항공, 해상등에서 동시에 통합관리하며 운용해야 하므로, 기존의 단일 탐사시스템 보다 훨씬 복잡하고 다 양한 현장 상황을 고려한 시스템이 요구된다. 실제의 자 원탐사는 많은 인력과 자금, 시간이 요구됨으로 사전에 충분히 시스템을 검증해야 한다. 전산기반의 시뮬레이션 검증의 경우, 현장상황의 재현이나 측정데이터의 반영을 통한 모델링이 어려워 대안이 필요하다.

\section{2 탐사자동화를 위한 로봇개발}

자원탐사 지역은 험지 및 극한환경이 매우 많다. 이러 한 환경에서 인력에 의한 데이터 수집이 이루어지고 있 다. 로봇을 이용하여 탐사를 자동화하면, 신뢰성과 정밀 도를 동시에 높일 수 있다. 그러나 자원탐사용 로봇의 개 발의 문제점은, 탐사대상인 자원은 다양한 형태로 자연에 존재하기 때문에 기지(Known)로서의 명확한 정의가 어 려워 로봇의 지능으로 구현하기에 한계가 있다[1]. 인력 에 의한 센싱의 경우, 다양한 경우에 따라 현장에서 유연 한 판단이 가능하나, 로봇의 경우, 이에 따른 충분한 지능 을 확보하지 못하고 있다. 탐사자동화의 관건은 지능이라 고도 할 수 있다.

\section{2. 자원탐사 시스템 최적화}

서론에서 언급한 두가지의 자원탐사 고도화 방법을 위 하여, 저자들은 자원탐사 축소모형 시스템을 개발하였다
[2,3]. 지하에 매장된 금속자원을 자장센서로 탐지하는 상 황을 상정하여, 그림 1 과 같이 목재 및 아크릴로 구성된 실험판 아래에 금속판을 설치하고 그림 2 와 같은 이동로 봇에 자장센서를 부착하여 실시간에 금속을 탐지하는 실 험을 하였다.

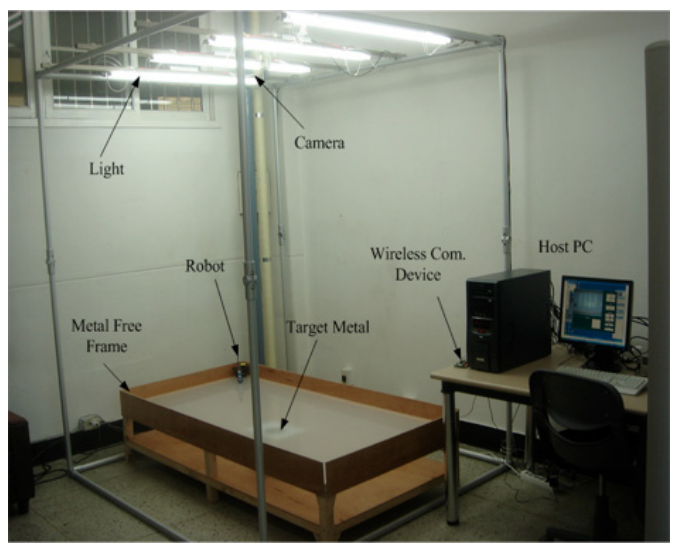

[그림 1] 기존의 자원탐사 시스템

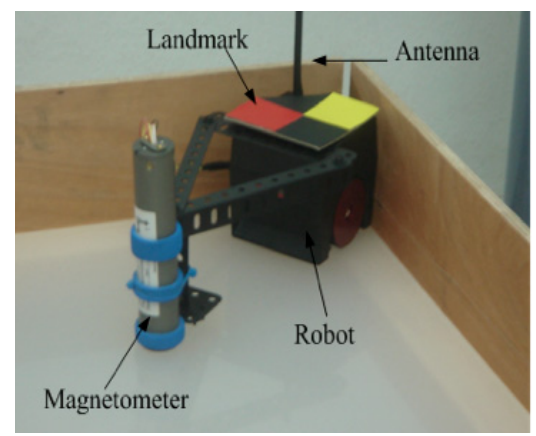

[그림 2] 차륜형 이동로봇

이러한 방법은 자원탐사의 에이전트와 실재 센싱 부분 을 재현함으로써, USN기반 융합형 탐사의 설계지침을 유효하게 얻을 수 있을 뿐 아니라, 로봇을 이용한 자동화 를 위한 지능시스템의 신뢰도 향상에 사용할 수 있다.

하지만 이 같은 시스템은 자기센서의 자장값에 로봇 본체의 자기장 영향을 받는 것이 불가피 하였다. 그리고 기존의 차륜형 로봇은 평면이외의 지형에서는 탐사의 제 약을 받을 수밖에 없으며, 다양한 환경에 대한 실험이 불 가능 하였다. 따라서 이같은 점의 개선방법으로 로봇본체 의 자기장영향을 최소화 하기위해 비철재료인 목제를 사 용하여 센서부를 본체로 부터 약 $1.5 \mathrm{~m}$ 이격시켜 놓았으 며, 기존의 차륜형 이동로봇에서 벗어나 다양한 환경에서 탐사를 할 수 있는 케이블카형 로봇을 개발하였다. 


\section{1 시스템 설명}

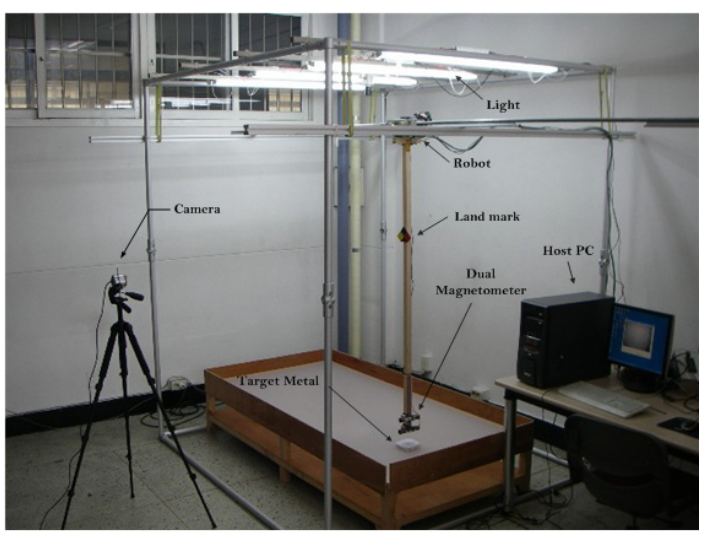

[그림 3] 자원탐사 시스템 전경

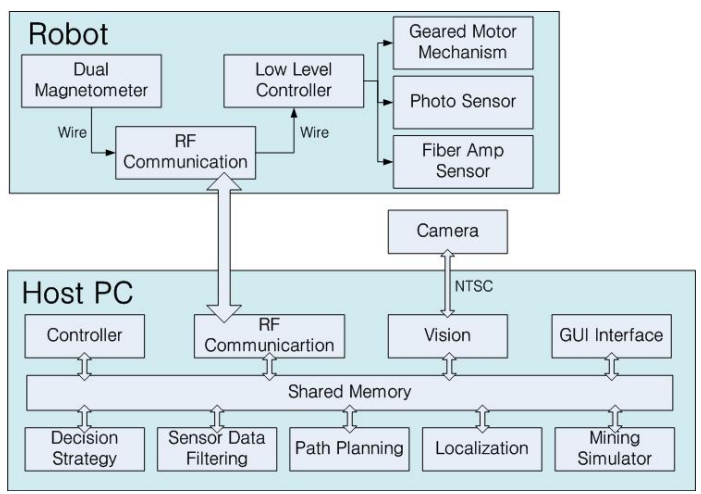

[그림 4] 자원탐사 시스템의 구성

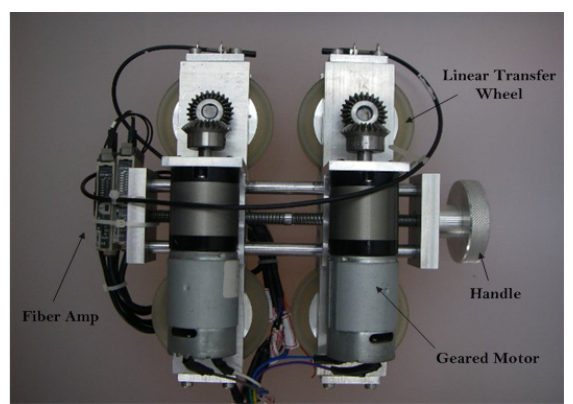

[그림 5] 케이블카형 로봇

자원탐사 시스템은 그림 3 과 같은 형태로 구성되어 있 다. 로봇의 위치는 측면과 상부의 카메라와 로봇에 부착 한 랜드마크(Land mark)에 의해 탐지되며, 유선(RS-232c) 으로 연결된 자장센서의 자장신호는 호스트컴퓨터로 전 달된다. 호스트 컴퓨터는 케이블카형 로봇을 움직이며 자
장센서 데이터를 수집하여 금속판의 위치를 탐지한다.

자원탐사 시스템은 그림 4 와 같이 로봇과 호스트 컴 퓨터로 구성되어있다. 호스트 컴퓨터는 로봇의 위치를 파 악하기 위한 비젼시스템과 화이버 센서(Fiber Amp)를 사 용하여 이동거리를 측정한다. 구동부 제어를 위해 기본적 인 컨트롤러를 탑재하고 있으며, 각각의 롤러는 독립적으 로 구동된다. 케이블카형 로봇은 그림 5 와 같은 형태로 개발되었으며, 핸들을 통해 케이블의 굵기에 따른 조절이 가능하게 설계하였다.

\section{2 비전 시스템의 설계}

이동로봇위에 부착된 사각형 랜드마크에는 2 가지색의 특정한 칼라마크가 부착되어 있으며, 이를 RGB로 인식 하여 마크위치를 찾아낸다. 일반적인 칼라추출의 경우, 화면상에서의 특정 RGB 값을 가지는 랜드마크의 색을 인식하는데 있어서, 일방적인 임계치 범위(Threshold range)로 정하기 때문에, 주변환경의 영향에 미묘한 색변 화로 임계치를 넘어선 경우는 로봇위치의 파악에 오차가 발생한다. 또한 임계치의 범위를 넓힐 경우, 주변의 색들 이 노이즈로 들어오기 때문에 정확한 색추출에 오차가 증가한다. 이러한 문제점을 해결하기 위하여, 본 연구에 서는 Mahalanobis Distance를 이용해 정확하게 랜드마크 의 위치를 추출하는 신뢰성 있는 방법을 도입했다. 이 기 법은 확률학에서 1936년 P.C. Mahalanobis에 의해 제안 된 것으로, 두가지 패턴 사이에 상관관계(Correlation)을 이용한다. 이 기법은 미지 대상물의 Sample set을 이용해 상사(Similarity)를 결정하는 것으로, 유클리드 거리 (Euclidean Distance) 와는 차이가 있다.

Mahalanobis Distance는 Multivariate Vector $x=\left(x_{1}, x_{2}, x_{3}, \ldots x_{P}\right)^{T}$ 의 공분산 행렬합(Covariance matrix summation)과 임의의 집합의 평균값인 $\mu=\left(\mu_{1}, \mu_{2}, \mu_{3}, \ldots . \mu_{P}\right)^{T}$ 으로부터 구해진다. 정의는 아래 의 식과 같다.

$$
D_{M}(x)=\sqrt{(x-\mu)^{T} \sum^{-1}(x-\mu)}
$$

Mahalanobis distance는 임의의 서로 다른 벡터 $\vec{x}, \vec{y}$ 비상사(Dissimilarity)의 경우, 아래의 식으로 구해진다.

$$
d(\vec{x}, \vec{y})=\sqrt{(\vec{x}-\vec{y})^{T} \sum^{-1}(\vec{x}-\vec{y})}
$$

만일 공분산(Covariance)행렬이 항등행렬(Identity matrix)일 경우, Mahalanobis distance는 유클리드거리 
(Euiclidean distance)가 된다. 이경우의 값은 아래 식으로 구해진다.

$$
\begin{aligned}
& d(\vec{x}, \vec{y})=\sqrt{\left(\sum_{i=1}^{P} \frac{\left(x_{i}-y_{i}\right)^{2}}{\sigma_{i}^{2}}\right.} \\
& \left(\sigma_{i} \text { 는 } x_{i}\right. \text { 의 표준편차) }
\end{aligned}
$$

$\mathrm{RGB}$ 로 구성된 화면상의 칼라를 하나의 패턴으로 정 의해, 기준이 되는 랜드마크의 칼라로부터, 대상칼라까지 의 Mahalanobis Distance를 구하면, 주변의 색변화에도 강하고, 인식 정확도가 높은 칼라인식이 가능하다. Mahalanobis Distance를 도입해, 랜드마크의 칼라를 인식 한 결과, 로봇 위치인식의 신뢰도와 정확도가 확실히 개 선되었다.

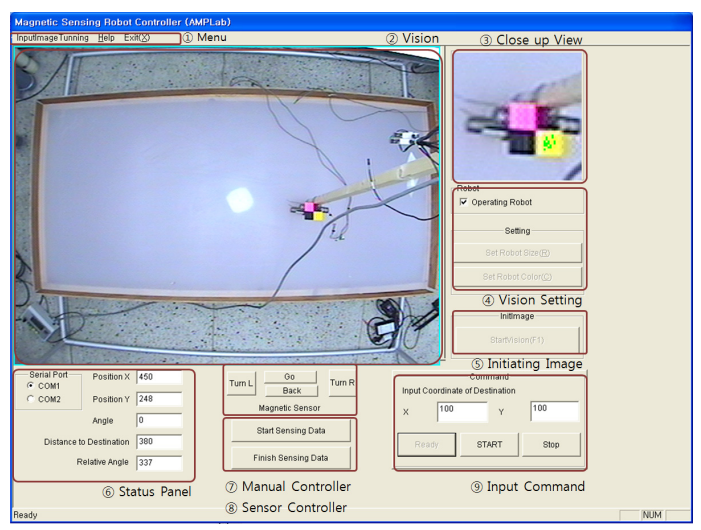

[그림 6] GUI

\subsection{GUI에 대한 설명}

효과적인 자원탐사 시스템을 구축하기 위해서는, 실시 간으로 탐지결과를 효율적으로 전달하는 모니터링용 GUI(Graphic User Interface)가 필요하다. 이를 위하여 그 림 6과 같은 GUI를 개발하였다. 이는 상부 카메라 화상 을 통해 로봇의 정보를 나타낸다. 측정목표물인 실험용 금속판의 위치는 반투명 아크릴판아래의 흰색으로 나타 나 있다. 화상에서 로봇의 위치를 인식하기 위해 랜드마 크를 근접 영상으로 표시하여 색상과 로봇의 크기를 지 정한다. 로봇은 주어진 시작 위치에서 좌표로 입력된 목 적지로 이동을 하면서 경로상의 각 위치의 좌표와 자장 데이터를 일정한 간격으로 수집해 호스트 컴퓨터로 전송 한다.
케이블카형 로봇의 자장 탐지 방법으로, 기존의 단일 자장 탐지[4]가 아니라, 복수의 자장센서를 탑재하여 자 장의 Gradient를 측정하는 센서를 탑재였다. 이러한 방법 을 사용하면, 신뢰도가 높은 탐지가 가능하다[5,6]. 이를 이용하여 실시간으로 금속판 탐지 실험을 실시하였다. 자 장센서의 방위는 그림 7과 같이 부착하였으며, 우수좌표 계이고 지지대에 두 자장센서사이의 간격을 조절할 수 있도록 하였다. 자장센서-1과 자장센서-2 사이의 거리는 등간격으로 $5,10,15,20 \mathrm{~cm}$ 로 조절하여 실시간 자장 탐 지 실험을 실시하였다. 로봇은 $0-100 \mathrm{~cm}$ 의 직선구간을 전 진하며, 금속판은 로봇이동의 이동선상의 중심인 $50 \mathrm{~cm}$ 상 에 위치한다. 금속판과 자장센서- 1 과의 거리는 $5 \mathrm{~cm}$ 인 조 건에서 실험을 실시하였다.

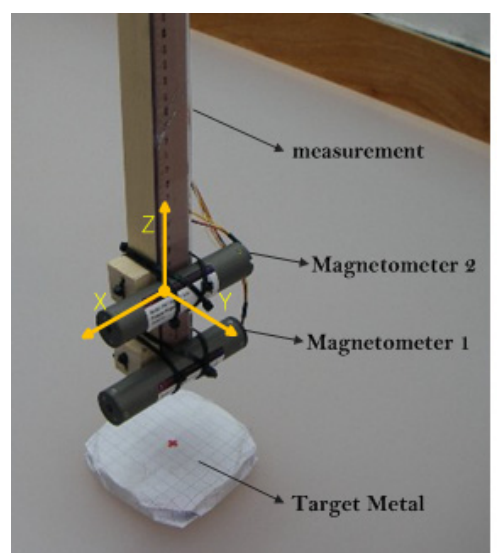

[그림 7] Gradient 센서를 탑재한 케이블카형 로봇

실험결과는 3차원 자장센서로부터 전송받은 Gradient 값으로 $\mathrm{Mx}, \mathrm{My}, \mathrm{Mz}$ 각 축은 단위를 사용하고 있으며, 이 를 통해 수평분력 $\mathrm{H}($ Horizontal), 전자력 $\mathrm{T}(\mathrm{Total})$ 를 계산 할 수 있다.

그림 8-12는 케이블카 로봇 시스템을 이용하여 자장센 서간의 거리가 $15 \mathrm{~cm}$ 일 때의 자장의 Gradient값을 측정한 결과이며, 그림 13-17은 그림 1과 같은 종래의 이동로봇 을 이용한 단일자장 측정방법을 사용한 결과이다. 목표 의 금속자원은 그래프의 $\mathrm{X}$ 축중앙부위근방에 매설되어 있었다. 실험결과에서 나타난것과 같이, Gradient값을 측 정한 경우, 중앙부위에서 급격한 자장의 변화가 나타나 정확한 측정이 가능하였다. 종래 방법의 경우, 상대적으 로 중앙부위의 변화가 약하여 자원탐지가 어려웠다. 이 로써 케이블카형 이동로봇 시스템을 이용한 경우가 명확 히 향상된 자원탐지가 가능함을 입증하였다.

이와 같은 시스템을 이용하여, 실재의 자원탐사의 설 계시, 센서배치 및 수량 최적화 및 탐사 경로계획등에 이

\section{3. 실험 및 고찰}


용할 수 있다. 또한 케이블카형 로봇은 로프등을 이용한 이동이 가능함으로써, 산악지형에서 자원탐사가 어려운 골짜기의 자장 탐사등에 활용 될 수 있다.

육상의 자원탐사와 같이 극한환경인 수중의 경우 로봇 을 적극적으로 도입하여 탐사를 자동화[7][8]해 나가고 있다. 본 시스템을 이용하여, 로봇의 지능화 및 센싱 신 뢰도를 향상시키면, 자원탐사에도 로봇을 이용한 자동화 도 향후 가능하다.

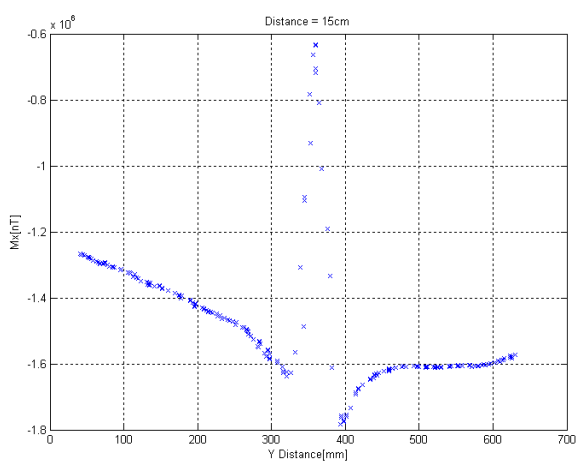

[그림 8] Mx, X축 방향 자장

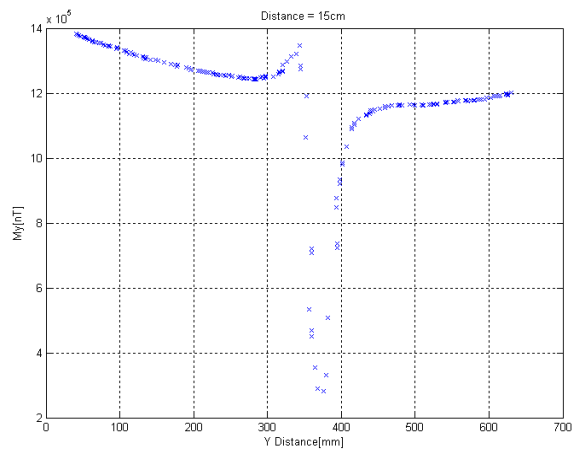

[그림 9] My, Y축 방향 자장

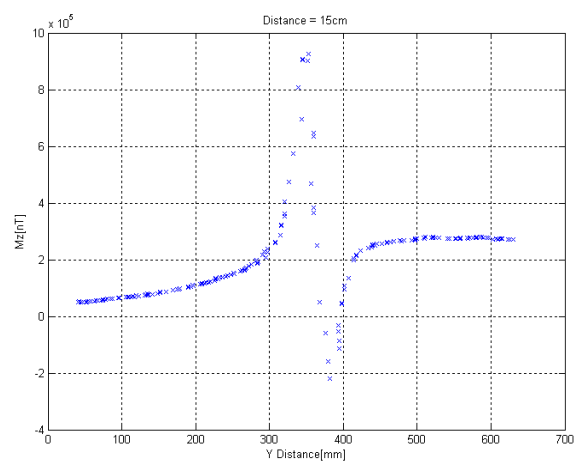

[그림 10] Mz, Z축 방향 자장

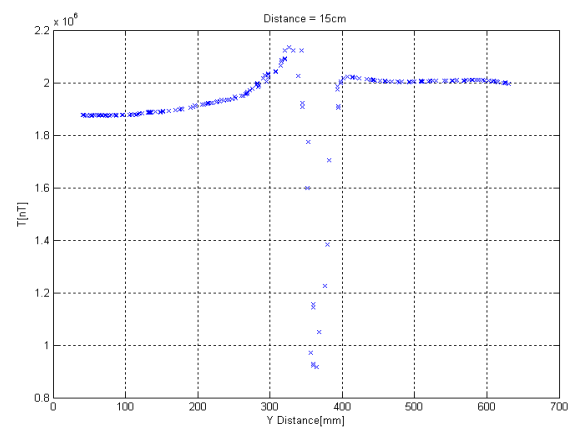

[그림 11] Total, 자장벡터의 Total

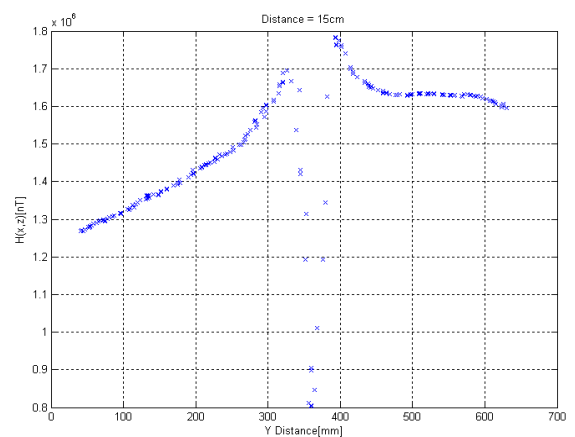

[그림 12] Horizontal, 자장벡터의 Horizontal

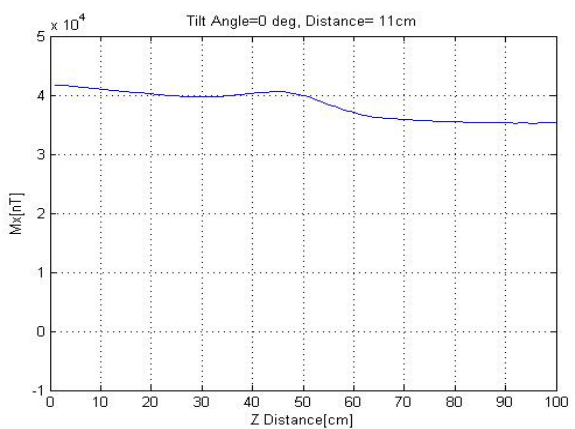

[그림 13] Mx, X축 방향 자장

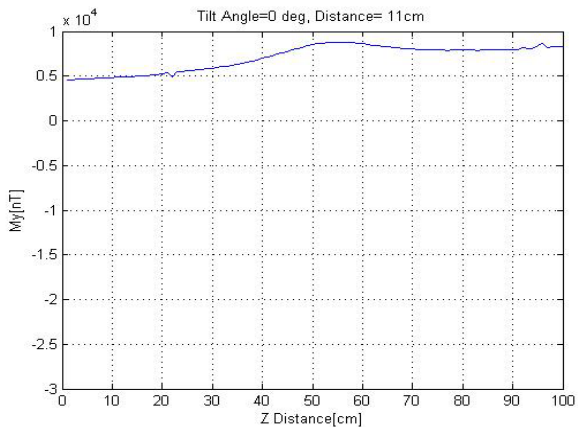

[그림 14] My, Y축 방향 자장 


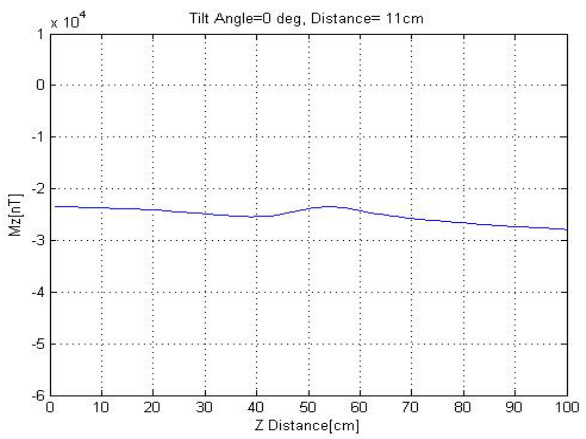

[그림 15] Mz, Z축 방향 자장

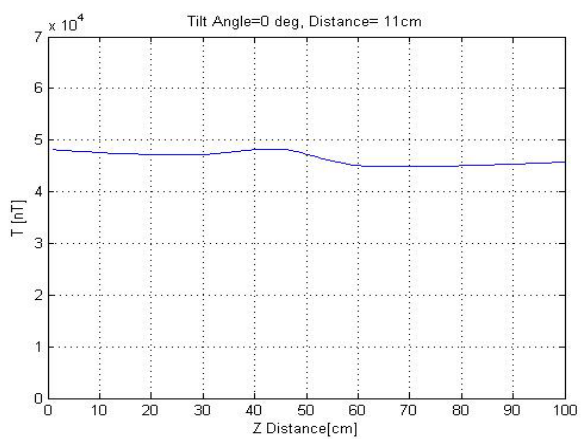

[그림 16] Total, 자장벡터의 Total

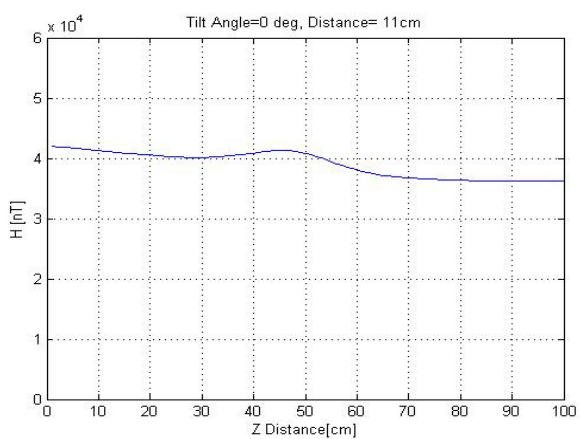

[그림 17] Horizontal, 자장벡터의 Horizontal

\section{4. 결론}

본 연구는 자원탐사의 최적화 및 자동화를 위한 탐사 환경 축소모형 시스템을 제안하고, 케이블카형 로봇을 이 용하여 자원탐사 최적화방법을 제시하였다.

수치적 모델링에 어려움이 많은 자원탐사 분야에 있어 서, 본 시스템과 같이 실제의 센서값 및 다양한 환경적인 요인의 변수 설정과 이를 통해 측정한 데이터를 기반으 로 한 설계 방법은 자원탐사의 최적화에 효과적이다.
새로운 에이전트의 개발 및 실험을 통해 USN기반 융 합형 자원탐사에 추가적 확장 가능성을 여는 기회가 될 수 있다. 본 시스템은 향후 탐사 자동화를 위한 이동로 봇 개발에 활용이 가능하다.

\section{참고문헌}

[1] Ota, J., Kurbayashi, D., and Arai, T., 2001, Introduction to Intelligent Robot; solution of path planning problems, Corona publishing. (in Japanese)

[2] 유선철, 정현기, 표주현, 윤중선, 2009a, 하드웨어축소 모형시스템을 이용한 자원탐사 시뮬레이션 시스템구 축, 2009년 춘계지질과학기술 공동학술대회 논문집, 185-186.

[3] 유선철, 정현기, 표주현, 윤중선, 2009b, 자원탐사 시 스템 구축을 위한 자동화 방법모색, 2009년 춘계지질 과학기술 공동학술대회 논문집, 455-456.

[4] Blakely, R. J., 1996, Potential Theory in Gravity and Magnetic Applications, Cambridge University Press.

[5] Stanley, J. M., 1977, Simplified magnetic interpretation of the geologic contact and thin dyke, Geophysics, 99, 1236-1240.

[6] Merril, R. T., McElhinny, M. W., and McFadden, Ph. L., 1983, The magnetic Field of the Earth, Academic Press.

[7] Ura., T., et al., 2004, Introduction to an AUV "r2D4" and its Kuroshima Knoll Survey Mission, Proc. of MTS/IEEE Oceans.

[8] Yu, S. and Ura, T., 2004, A system of Multi-AUV Interlinked with a Smart Cable for Autonomous Inspection of Underwater Structures, International Journal of Offshore Structures and Polar Engineering, 14(4), 265-273.

\section{유 선 철(Son-Cheol $\mathrm{Yu})$}

[정회원]

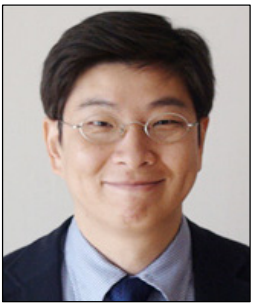

- 2000년 9월 : University of Tokyo (공학석사)

- 2003년 9월 : Universit of Tokyo (공학박사)

- 2004년 3월 2008년 2월 : University of Hawaii 연구원

- 2008년 3월 20010년 2월 : 부 산대 기계공학부 조교수

- 2010년 3월 현재 : 포항공과대학교 해양대학원 조교수

<관심분야>

로봇공학, 자동화, 해중기계 


\section{표 주 현(Ju-Hyun Pyo)}

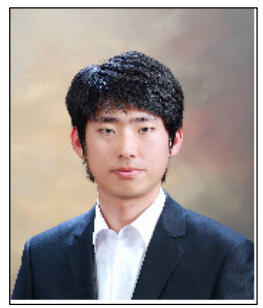

- 2010년 2월 : 부산대학교 기계공 학부 (공학사)

- 2010년 3월 현재 : 포항공과 대학교 해양대학원 연구원

<관심분야>

로봇공학, 자동화

\section{정 현 기(Hyun-Key Jung)}

[정회원]

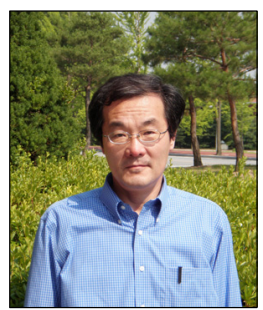

- 1981년 2월 : 서울대학교 자원공 학과 (공학석사)

- 1986년 2월 : 서울대학교 자원공 학과 (공학박사)

- 1986년 현재 : 한국지질자원 연구원 책임연구원

- 2010년 현재 : UST 물리탐사 공학과 전공책임교수

<관심분야>

지구물리탐사, 광물·지하수·유물 탐사계측시스템개발

\section{윤 중 선(Joong-Sun Yoon)}

[정회원]

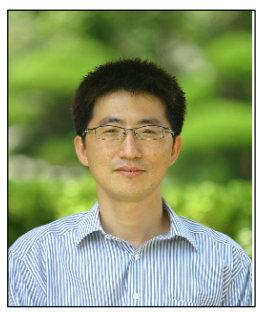

- 1981년 2월 : 서울대학교 공학사

- 1983년 2월 : 서울대학교 공학석 사

- 1988년 8월 : 리하이대학교 공학 박사

- 1990년 2월 1991년 6월 : 삼 성전자 연구원

- 1991년 7월 1993년 7월 : 금 오공대 조교수

- 1993년 7월 현재 : 부산대학교 교수

<관심분야>

로봇공학, 제어자동화시스템
이 정 익(Jeong-Ick Lee)

[정회원]

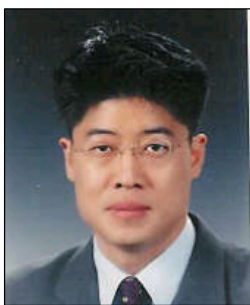

- 1991년 2월 : 한양대학교 기계공 학과 (공학사)

- 1993년 2월 : 한양대학교 기계공 학과 (공학석사)

- 1999년 8월 : 한양대학교 기계공 학과 (공학박사)

- 1993년 1999년 : 대우전자 연 구센터 선임연구원

- 2000년 3월 2006년 2월 : 용인송담대학 자동차공학 과 교수

- 2007년 3월 현재 : 인하공업전문대학 기계설계과 교수

<관심분야>

CAD/CAM/CAE, Factory Automation, Manufacturing Automation, Mold Injection, Ubiquitous Eng., MEMS, Biomechanics

조 성 호(Sung-Ho Cho)

[준회원]

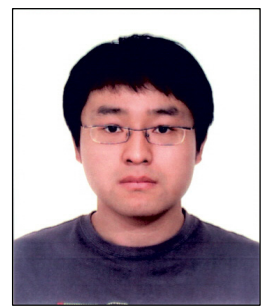

- 2008년 2월 : 충남대학교 전기정 보통신공학부 (공학사)

- 2010년 9월 현재 : 과학기술 연합대학원 대학교(UST) 물리탐 사공학과 석사재학

<관심분야>

지구물리탐사, 광물·지하수·유물 탐사계측시스템개발

김 태 진(Tae-Jin Kim)

[정회원]

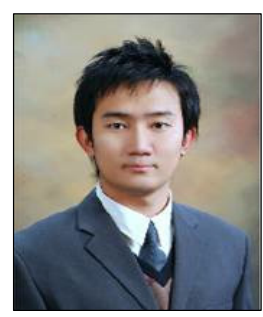

- 2010년 2월 : 부산대학교 기계공 학부 (공학사)

- 2010년 1월 현재 : 대우조선 해양
<관심분야>

로봇공학, 기계설계 